\title{
Translating knowledge to practice: optimizing the use of guidelines
}

\author{
A. R. Gagliardi* \\ Minimal Risk, Research Ethics Board, University Health Network and University of Toronto, Toronto, Ontario, Canada
}

\begin{abstract}
Guidelines support health care decision-making but continue to be underused, therefore more research is needed on how they can be better developed and implemented. The same is true of mental health care, for which there is recent growing interest in improving care delivery and associated outcomes by optimizing the use of mental health care guidelines. This editorial describes the key concepts from accumulated research on guideline implementation to suggest a number of avenues for research on implementation of mental health care guidelines.
\end{abstract}

First published online 22 May 2012

Key words: Guideline development, guideline implementation, guidelines, mental health.

\section{Need to translate mental health research to practice}

Guidelines are syntheses of best available evidence that support decision-making by clinicians, managers and policy-makers about the organization and delivery of health care, but population-based studies show that guidelines produced by prominent agencies for chronic and acute conditions continue to be underused (Browman et al. 1995; McGlynn et al. 2003; Brown et al. 2004; FitzGerald et al. 2006; Grimshaw et al. 2006; Latosinsky et al. 2007; Francke et al. 2008). Modelling by the World Health Organization found that for cancer, a third of the cases could be prevented, another third cured and the rest effectively managed if care consistently complied with the existing guidelines (World Health Organization: Cancer, 2012). The same may be true of other conditions, including mental health, for which studies show that many patients with mental health disorders do not receive guideline-recommended care for those or other medical conditions (Becker et al. 2011; Kilbourne et al. 2011). Thus it is imperative that we improve or seek new ways of promoting guideline use.

Many countries have launched policies and programmes to monitor the quality of mental health care (Spaeth-Rublee et al. 2010). This alone may not be sufficient to bring about improvements in the organization, delivery and outcome of mental health services. Instead, improvements may be needed along a spectrum of activities, including guideline development and implementation. Others have

\footnotetext{
* Address for correspondence: Professor Anna R. Gagliardi, Toronto General Research Institute, 200 Elizabeth Street, Toronto, Ontario M5G2C4, Canada.

(Email: anna.gagliardi@uhnresearch.ca)
}

demonstrated the complexity of developing guidelines for mental health, and have adapted the existing methods for doing so (Barbui et al. 2010). A recent systematic review of 187 eligible studies that focused on implementation of mental health research into practice found that most publications were theoretical or policy discussions (Goldner et al. 2011). Empirical research largely consisted of quantitative, qualitative or mixed method evaluations of interventions to promote changes in provider knowledge or behaviour, shared decision-making between patients and providers or public campaigns to enhance mental health literacy. Of particular note, the review identified that all the studies were published quite recently, between 2007 and 2010, highlighting growing interest in optimizing use of mental health care guidelines and associated beneficial outcomes, and the need for more research on how to effectively do so.

The study of guideline implementation and use is not new, so a review of the key concepts drawn from that body of knowledge may guide ongoing practice and research in mental health. In this editorial, those key concepts are organized according to the steps in the iterative cycle of guideline implementation, including tailoring guidelines, assessing barriers of guideline use, selecting and tailoring implementation interventions and monitoring guideline use and outcomes (Graham et al. 2006).

\section{Tailoring guidelines}

Evidence suggests that we could modify the content and format of guidelines to facilitate their use (Grilli \& Lomas, 1994; Shekelle et al. 2000; Michie \& Johnston, 2004; Michie \& Lester, 2005; Cochrane et al. 
2007; Dobbins et al. 2009). Including information in guidelines beyond the clinical recommendations may help users to themselves implement the guidelines by promoting greater understanding of how they are to overcome barriers, stimulating confidence in the ability to practice the recommended behaviour, leading to greater intent to use guidelines, and possibly actual use. The concept of implementability was first defined by Shiffman as characteristics of guidelines that may enhance their implementation by users, who issued criteria for generating guideline recommendations with actionable wording (Shiffman et al. 2005). To further investigate the concept of implementability, we reviewed the medical literature to identify features desired by different users or associated with guideline use (Gagliardi et al. 2009). The guideline implementability framework included 22 elements organized within eight domains: adaptability, usability, relevance, validity, applicability, communicability, resource implications, implementation and evaluation. Subsequent analysis of 20 high-quality guidelines on various clinical indications found that most did not contain implementability elements, highlighting numerous opportunities to potentially improve guideline development and use by integrating one or more of these elements (Gagliardi et al. 2011). In collaboration with the Guidelines International Network (G-I-N) and several member agencies, we are identifying and developing tools that guideline developers, implementers or users can apply to address Resource Implications (equipment or technology needed; industrial standards; policies governing their use; type and number of health professionals needed to deliver services; education, training or competencies needed by staff to deliver services; anticipated changes in workflow or processes during or after adoption), Implementation (identifying barriers associated with adoption; selecting and tailoring implementation strategies that address barriers) and Evaluation (tools based on performance measures to assess baseline and post intervention compliance with guidelines). These tools will be pilot tested and then ultimately packaged with guidelines for various clinical indications to assess their impact, alone and combined with other strategies. As part of this effort we would welcome the opportunity to collaboratively examine the implementability of mental health guidelines, and develop and evaluate the impact of implementability tools that support guideline-recommended mental health care delivery.

\section{Identifying barriers of guideline use}

Many factors intrinsic and extrinsic to guidelines challenge their use, including guideline characteristics (quality of format and content), and individual (provider characteristics), institutional (capacity to collect, adapt, share and apply evidence) and system level (policies and resources) issues (Carter et al. 1995; Fleuren et al. 2004; Davis et al. 2006, 2007). Furthermore, many guidelines are passively distributed. A repeat survey of Canadian guideline developers in 1994, 2002 and 2008 found that a few implemented their guidelines, citing limited resources (Kryworuchko et al. 2009). A survey of the guideline developers in Africa, Asia, Europe, Latin America, the United States and United Kingdom found that most believed that the target users should be responsible for implementation (Lavis et al. 2008). Through interviews, we found that the professionals who fund, manage and deliver health services lack knowledge about how to implement the guidelines, and may not have the mandate or resources to do so (not yet published). In the mental health arena, education, tools and resources are needed to guide and support all stages of guideline implementation, including barrier assessment. Recommendations have been issued to help mental health care professionals address the barrier of patient adherence (Velligan et al. 2010). Additional research is needed to identify and describe other intrinsic and extrinsic barriers specific to the implementation and use of mental health care guidelines.

\section{Selecting and tailoring interventions to promote guideline use}

Considerable research has examined the effectiveness of strategies to implement guidelines, including educational (materials and meetings), social engagement (opinion leaders and educational outreach), embedding (clinical support systems and reminders) and incentive (audit and feedback and pay-forperformance) approaches. These strategies can have a small to moderate impact either alone or in combination, but not consistently (O'Brien et al. 1997, 2001; Davis et al. 1999; Wolff et al. 2004; Garg et al. 2005; Grimshaw et al. 2006; Jamtvedt et al. 2006; Doumit et al. 2007; Mehrotra et al. 2009). Despite the variable impact, there is little evidence to guide the selection of implementation interventions for any given clinical indication or context. Practically speaking, a number of issues should be considered. The interventions must address specific barriers identified through previous research or a needs assessment. In addition to the barriers, the needs assessment should identify the current state of practice with respect to the guidelines, including awareness, acceptance, adoption and adherence, which comprise the Phases of Change (Pathman 
et al. 1996). A different implementation strategy may be needed if stakeholders are aware and accepting of a guideline, but are impeded in adopting it by organizational or system issues. Although single interventions may have comparable impact compared to multipronged interventions (Grimshaw et al. 2004), if multiple interventions are applied simultaneously, it may not be clear which component was influential or which component to modify if there is little change. The implementation process is ideally cyclical so it may be best to first implement and evaluate the impact of one intervention before modifying it or packaging it with additional interventions. Research shows that in-person contact is an important predictor of knowledge use, so involvement of a facilitative intermediary is likely to prove beneficial (Innvaer et al. 2002; Ouimet et al. 2006). Feasibility, cost, probable impact and unintended consequences associated with interventions or their impact must also be considered. Given these numerous issues assistance is clearly needed to more systematically guide the selection of implementation strategies appropriate to a given context, including mental health care.

There is some evidence to support the need for tailoring of interventions. A recent Cochrane systematic review of 26 randomized controlled trials found that interventions that had been tailored to address identified barriers were more likely to improve professional practice compared with either no intervention or dissemination of guidelines (Baker et al. 2010). However, most studies provided little information about how interventions were tailored so the review concluded that there is insufficient evidence on the most effective approaches for tailoring. Therefore, we examined select literature to identify the factors that appear to positively influence the impact of interventions, and which warrant further research to establish their effectiveness as tailoring strategies (Gagliardi, 2011). For example, the impact of educational strategies could be improved by focusing on topics involving less complex behaviour, offering a series of events, including interactive components and opportunities for reflection, and requesting commitments for behavioural change. The practice and impact of self-assessment could be improved by better supporting health professionals with training, tools and guidance. The impact of public reporting of performance data could be improved by optimizing the content, format and delivery of this information, and by periodic and ongoing rather than one-time reporting, as could audit and feedback data. Opinion leader interventions could be improved if multiple methods were used to identify and train the opinion leaders, the opinion leaders served in a variety of roles (educate or persuade, contextualize and assist with implementation) the participants were given multiple opportunities to interact with the opinion leaders, and non-physicians were considered for the role of opinion leaders. Broader systematic reviews of tailoring strategies that consider research from different disciplines and featuring a variety of approaches are recommended. Non-traditional systematic reviews that explain 'what works for whom, in what circumstances, and in what respect' are becoming more common, and include realist, narrative and ethnographic approaches (Britten et al. 2002; Greenhalgh et al. 2005; Pawson et al. 2005). Primary research is also needed to develop, implement and test the effectiveness of tailored interventions. Such investigations are needed in the area of mental health care, and would contribute to the larger body of knowledge on how to optimize interventions for implementing guidelines.

\section{Evaluating guideline implementation, use and outcomes}

As mentioned, guideline implementation is meant to be iterative. Following implementation, guideline use and outcomes should be monitored, and the findings used to inform ongoing quality improvement efforts. Although mental health care quality indicators have been rigorously developed and form the basis of national and subnational monitoring initiatives, the same issues that challenge performance measurement in other health care sectors influence the effectiveness of these programmes, including limited evidence regarding appropriate care upon which to base indicators, lack of coordination and common indicators across programmes and lack of information infrastructure to capture descriptive clinical data (Kilbourne et al. 2010; Waraich et al. 2010; Pincus et al. 2011). Time and resources will lead to improvements in data collection. In the meantime, there are several factors that must be considered when planning how to evaluate the impact of guideline implementation.

First, it is important to evaluate the completeness and success of the chosen implementation strategy. Adoption of an innovation is not a discrete event that can be assessed as a binary (yes/no) measure (Dopson, 2007). There are different degrees of adoption (none, partial, complete and customized) and this can change over time, therefore longitudinal evaluation is needed. Implementation fidelity is defined as the degree to which an intervention is delivered and/or used as intended and, unless measured, it cannot be determined whether an outcome is associated with the intervention, and therefore whether and how to refine the intervention (Carroll et al. 2007). Decisions must also be made about what to 
measure, and how. The measures may include immediate, intermediate and longer-term outcomes. For example, one may wish to assess reaction to the implementation strategy (satisfaction, participation, perceived effort, applicability, attitude and confidence), learning (knowledge, skill and intent to apply learning), behaviour (application of learning in practice, selfevaluation, nature of changes and if sustained) and outcomes (volume, percentages, timescales or other quantifiable performance measures relevant to clinical care or qualitative views about the nature of outcomes) (Kirkpatrick \& Kirkpatrick, 2006). How to undertake measurement includes consideration of the level of impact, and the models. The level may be influenced by the specific measure, availability of data and what is appropriate to report, and includes individual (provider and patient), organizational, system and population level impact. The models refer to theories or frameworks that suggest or explain factors that influence the potential impact of an intervention or their interrelationship, which informs data collection and analysis. Numerous models are available by which to plan and evaluate the impact of guideline implementation (Estabrooks et al. 2006; Sarjeant et al. 2011). The methods of evaluation are dependent on the measures chosen and sources of data by which to evaluate those measures, but may include quantitative, qualitative or mixed methods.

\section{Conclusions}

Much remains to be learned about how best to promote the use of guidelines but several decades of research has provided a framework and methods by which to more thoughtfully do so. Drawing on this research has revealed a number of avenues for research on implementation of guidelines in the mental health care sector. These include:

(1) Examining the implementability of mental health care guidelines.

(2) Developing and evaluating the impact of implementability tools that support guidelinerecommended mental health care delivery.

(3) Identifying and describing intrinsic and extrinsic barriers specific to the implementation and use of mental health care guidelines.

(4) Developing and offering educational interventions, tools and resources for mental health care guideline developers, implementers and users to enable them to carry out all stages of guideline implementation.

(5) Exploring the relevance of various implementation strategies to the mental health care context, and developing associated guidance for selecting appropriate implementation strategies.
(6) Reviewing the mental health care literature using a variety of systematic approaches to identify strategies for tailoring guideline implementation.

(7) Undertaking primary research to develop, implement and evaluate the effectiveness of interventions tailored specifically for implementing mental health care guidelines.

Ongoing research will lead to improvements in the guidelines themselves, and in the methods for implementing the guidelines. Since the study of implementation interventions in mental health is relatively new, the opportunity exists to rigorously design and describe interventions from the outset to more rapidly achieve a body of knowledge that supports the implementation of current and future mental health care and associated guidelines.

\section{Declaration of Interest:}

None

\section{References}

Baker R, Camosso-Stefinovic J, Gillies C, Shaw EJ, Cheater F, Flottorp S, Robertson N (2010). Tailored interventions to overcome identified barriers to change: effects on professional practice and health care outcomes. Cochrane Database Systematic Reviews 3, CD005470.

Barbui C, Dua T, van Ommeren M, Yasamy MT, Fleishcmann A, Clark N, Thornicroft G, Hill S, Saxena S (2010). Challenges in developing evidence-based recommendations using the GRADE approach: the case of mental, neurological and substance use disorders. Public Library of Science Medicine 7, e1000322.

Becker MA, Martinez-Tyson D, DiGennaro J, Ochshorn E (2011). Do Latino and non-Latino White Medicaid-enrolled adults differ in utilization of evidence-based treatment for major depressive disorder? Journal of Immigrant Minority Health 13, 1048-1054.

Britten N, Campbell R, Pope C, Donovan J, Morgan M, Pill R (2002). Using meta ethnography to synthesize qualitative research: a worked example. Journal of Health Services Research and Policy 7, 209-215.

Browman GP, Levine MN, Mohide A, Hayward RSA, Pritchard KI, Gafni A, Laupacis A (1995). The practice guidelines development cycle: a conceptual tool for practice guidelines development and implementation. Journal of Clinical Oncology 13, 502-512.

Brown LC, Johnson JA, Majumdar SR, Tsuyuki RT, McAlister FA (2004). Evidence of suboptimal management of cardiovascular risk in patients with type 2 diabetes mellitus and symptomatic atherosclerosis. Canadian Medical Association Journal 171, 1189-1192.

Carroll C, Patterson M, Wood S, Booth A, Rick J, Balain S (2007). A conceptual framework for implementation fidelity. Implementation Science 2, 40.

Carter AO, Battista RN, Hodge MJ, Lewis S, Basinski A, Davis D (1995). Report on activities and attitudes of 
organizations active in the clinical practice guidelines field. Canadian Medical Association Journal 153, 901-907.

Cochrane LJ, Olson CA, Murray S, Dupuis M, Tooman T, Hayes S (2007). Gaps between knowing and doing: understanding and assessing the barriers to optimal health care. Journal of Continuing Education in the Health Professions 27, 94-102.

Davis D, O'Brien MA, Freemantle N, Wolf FM, Mazmanian P, Taylor-Vaisey AL (1999). Impact of formal continuing medical education: do conferences, workshops, rounds, and other traditional continuing education activities change physician behavior? Journal of the American Medical Association 282, 867-874.

Davis D, Mazmanian PE, Fordis M, Van Harrison R, Thorpe KE, Perrier L (2006). Accuracy of physician self-assessment compared with observed measures of competence. Journal of the American Medical Association 296, 1094-1102.

Davis H, Powell A, Rushmer R (2007). Healthcare professionals' views on clinician engagement in quality improvement (http://www.health.org.uk/publications/ research_reports/clinician_engagement.html).

Dobbins M, Hanna SE, Ciliska D, Manske S, Cameron R, Mercer SL, O'Mara L, Decorby K, Robeson P (2009). A randomized controlled trial evaluating the impact of knowledge translation and exchange strategies. Implementation Science 4, 61.

Dopson $S$ (2007). A view from organizational studies. Nursing Research 56, 72-77.

Doumit G, Gattellari M, Grimshaw J, O'Brien MA (2007). Local opinion leaders: effects on professional practice and health care outcomes. Cochrane Database Systematic Reviews 1, CD000125.

Estabrooks CA, Thompson DS, Lovely JE, Hofmeyer A (2006). A guide to knowledge translation theory. Journal of Continuing Education in the Health Professions 26, 25-36.

FitzGerald JM, Boulet LP, McIvor RA, Zimmerman S, Chapman KR (2006). Asthma control in Canada remains suboptimal: the reality of asthma control (TRAC) study. Canadian Respiratory Journal 13, 253-259.

Fleuren M, Wiefferink K, Paulussen T (2004). Determinants of innovation within health care organizations. International Journal for Quality in Health Care 16, 107-123.

Francke AL, Smit MC, de Veer AJE, Mistiaen P (2008). Factors influencing the implementation of clinical guidelines for health care professionals: a systematic meta-review. BMC Medical Informatics and Decision Making 8,38 .

Gagliardi AR (2011). Tailoring interventions: examining the evidence and identifying gaps. Journal of Continuing Education in the Health Professions 31, 276-282.

Gagliardi AR, Brouwers MC, Palda VA, Lemieux-Charles L, Grimshaw JM (2009). An exploration of how guideline developer capacity and guideline implementability influence implementation and adoption: study protocol. Implementation Science 4, 36.

Gagliardi AR, Brouwers MC, Palda VA, Lemieux-Charles L, Grimshaw JM (2011). How can we improve guideline use? A conceptual framework of implementability.

Implementation Science 6, 26.
Garg AX, Adhikari NK, McDonald H, Rosas-Arellano P, Devereaux PJ, Beyene J, Sam J, Haynes RB (2005). Effects of computerized clinical decision support systems on practitioner performance and patient outcomes. Journal of the American Medical Association 293, 1223-1238.

Goldner EM, Jeffries V, Bilsker D, Jenkins E, Menear M, Petermann L (2011). Knowledge translation in mental health: a scoping review. Healthcare Policy 7, 83-120.

Graham ID, Logan J, Harrison MB, Straus SE, Tetroe J, Caswell W, Robinson N (2006). Lost in knowledge translation: time for a map? Journal of Continuing Education in the Health Professions 26, 13-24.

Greenhalgh T, Roberts G, Macfarlane F, Bate P, Kyriakidou O, Peacock R (2005). Storylines of research in diffusion of innovation: a meta-narrative approach to systematic review. Social Science and Medicine 61, 427-430.

Grilli R, Lomas J (1994). Evaluating the message: the relationship between compliance rate and the subject of a practice guideline. Medical Care 32, 202-213.

Grimshaw JM, Thomas RE, MacLennan G, Fraser C, Ramsay CR, Vale L, Whitty P, Eccles MP, Matowe L, Shirran L, Wensing M, Dijkstra R, Donaldson C (2004). Effectiveness and efficiency of guideline dissemination and implementation strategies. Health Technology Assessment 8, $1-72$.

Grimshaw J, Eccles M, Thomas R, MacLennan G, Ramsay C, Fraser C, Vale L (2006). Toward evidence-based quality improvement. Evidence (and its limitations) of the effectiveness of guideline dissemination and implementation strategies 1966-1998. Journal of General Internal Medicine 21, 14-20.

Innvaer S, Vist G, Trommald M, Oxman A (2002). Health policy-makers' perceptions of their use of evidence: a systematic review. Journal of Health Services Research and Policy 7, 239-244.

Jamtvedt G, Young JM, Kristoffersen DT, O’Brien MA, Oxman AD (2006). Audit and feedback: effects on professional practice and health care outcomes. Cochrane Database Systematic Reviews 2, CD000259.

Kilbourne AM, Keyser D, Pincus HA (2010). Challenges and opportunities in measuring the quality of mental heath care. Canadian Journal of Psychiatry 55, 549-557.

Kilbourne AM, Pirraglia PA, Zongshan L, Bauer MS, Charns MP, Greenwald D, Welsh DE, McCarthy JF, Yano E (2011). Quality of general medical care among patients with serious mental illness. Psychiatric Services 62, 922-928.

Kirkpatrick DL, Kirkpatrick JD (2006). In Evaluating Training Programs. 3rd edn. Berrett-Koehler Publishers Inc.: San Francisco, CA.

Kryworuchko J, Stacey D, Bai N, Graham ID (2009). Twelve years of clinical practice guideline development, dissemination and evaluation in Canada (1994 to 2005). Implementation Science 4, 49.

Latosinsky S, Fradette K, Lix L, Hildebrand K, Turner D (2007). Canadian breast cancer guidelines: have they made a difference? Canadian Medical Association Journal 176, 771-776.

Lavis JN, Oxman AD, Moynihan R, Paulsen EJ (2008). Evidence-informed health policy - interviews with the 
directors of organizations that support the use of research evidence. Implementation Science 3, 55.

McGlynn EA, Asch SM, Adams J, Keesey J, Hicks J, DeCristofaro A, Kerr EA (2003). The quality of health care delivered to adults in the United States. New England Journal of Medicine 348, 2635-2645.

Mehrotra A, Damberg CL, Sorbero ME, Teleki SS (2009). Pay for performance in the hospital setting: what is the state of the evidence? American Journal of Medical Quality 24, 19-28.

Michie S, Johnston M (2004). Changing clinical behaviour by making guidelines specific. British Medical Journal 328, 343-345.

Michie S, Lester K (2005). Words matter: increasing the implementation of clinical guidelines. Quality and Safety in Health Care 14, 367-370.

O'Brien MA, Oxman AD, Davis DA, Haynes RB, Freemantle N, Harvey EL (1997). Educational outreach visits: effects on professional practice and health care outcomes. Cochrane Database Systematic Reviews 4, CD000409.

O'Brien MA, Freemantle N, Oxman AD, Wolf F, Davis DA, Herrin J (2001). Continuing education meetings and workshops: effects on professional practice and health care outcomes. Cochrane Database Systematic Reviews 1, CD003030.

Ouimet M, Landry R, Amara N, Belkhodja O (2006). What factors induce health care decision-makers to use clinical guidelines? Evidence from provincial health ministries, regional health authorities and hospitals in Canada. Social Science and Medicine 62, 964-976.

Pathman DE, Konrad TR, Freed GL, Freeman VA, Koch GG (1996). The awareness-to-adherence model of the steps to clinical guideline compliance. Medical Care 34, 873-889.

Pawson R, Greenhalgh T, Harvey G, Walshe K (2005). Realist review - a new method of systematic review designed for complex policy interventions. Journal of Health Services Research and Policy 10, 21-34.
Pincus HA, Spaeth-Rublee B, Watkins KE (2011). The case for measuring quality in mental health and substance abuse care. Health Affairs 30, 730-736.

Sarjeant J, Borduas F, Sales A, Klein D, Lynn B, Stenerson H (2011). CPD and KT: models used and opportunities for synergy. Journal of Continuing Education in the Health Professions 31, 167-173.

Shekelle PG, Kravitz RL, Beart J, Marger M, Wang M, Lee M (2000). Are non-specific guidelines potentially harmful? A randomized comparison of the effect of nonspecific versus specific guidelines on physician decision making. Health Services Research 34, 1429-1448.

Shiffman RN, Dixon J, Brandt C, Essaihi A, Hsiao A, Michel G, O'Connell R (2005). The GuideLine Implementability Appraisal (GLIA): development of an instrument to identify obstacles to guideline implementation. BMC Medical Informatics and Decision Making 5, 23.

Spaeth-Rublee B, Pincus HA, Huynh PT (2010). Measuring quality of mental health care: a review of initiatives and programs in selected countries. Canadian Journal of Psychiatry 55, 9.

Velligan DI, Weiden PJ, Sajatovic M, Scott J, Carpenter D, Ross R, Docherty JP (2010). Strategies for addressing adherence problems in patients with serious and persistent mental illness: recommendations from the Expert Consensus Guidelines. Journal of Psychiatric Practice 16, 306324.

Waraich P, Saklikar RS, Arube D, Jones W, Haslam D, Hamill K (2010). Quality measures for primary mental healthcare. Quality and Safety in Health Care 19, 519-525.

Wolff AM, Taylor SA, McCabe JF (2004). Using checklists and reminders in clinical pathways to improve hospital inpatient care. Medical Journal of Australia 181, 428-431.

World Health Organization (2012). Cancer. Fact Sheets 297 (http://www.who.int/mediacentre/factsheets/fs297/en/) Assessed 3 April 2012. 